\title{
Life situation and participation as experienced by adult patients in palliative home care
}

\author{
Lise-Lotte Jonasson ${ }^{1 *}$, Peggy Lindö ${ }^{2}$, Tina Lindh ${ }^{3}$ and Karin Josefsson ${ }^{4}$ \\ ${ }^{1}$ Faculty of Caring Science, Work Life and Social Welfare, University of Borås, Sweden \\ ${ }^{2}$ Occupational Health Nurse, Laholmshälsan, Sweden \\ ${ }^{3}$ Public health nurse, Mölndals municipality, Sweden \\ ${ }^{4}$ Faculty of Caring Science, Work Life and Social Welfare, University of Borås, Sweden
}

\begin{abstract}
Background: Many patients are currently cared for at the end-of-life stage at home, and the number is expected to increase. The patient's participation is a prerequisite for good care, which also relates to ethical principles and evidence-based action.

Aim: To describe adult patients' experiences of their life situation and their participation in palliative home care.

Method: A reflective lifeworld approach and a phenomenological meaning analysis were conducted. Six adult patients in palliative home care were interviewed in Sweden during 2018.

Results: One essential meaning and five elements of that meaning describe adult patients' life situations and participation in their palliative home care. The essential meaning referred to needing and endeavouring to live as usual and taking responsibility for life. The five essential elements were: The home should be my home, where I know who is coming through the door; I should know when help is coming and be included when decisions are made; routines should be maintained, but without booking up tomorrow; accept death, feel hope, and plan for relatives after my death; and be aware that death is imminent, but not know when it will come.

Conclusions: Participation in palliative home care can be maintained and improved by caregivers behaving as guests in the patient's home, building up the patient's trust, showing consideration for patients and their relatives, promoting patients living everyday life as they previously had, asking about the patient's habits, and giving patients time and continuity in the caregiving relationship. Education should focus on how to have supportive conversations with a patient who is dying and preparing for death.
\end{abstract}

\section{Background}

The end-of-life can be described as a unique experience in which each person has individual needs and desires for calmly meeting their death [1]. It is important for patients to continue to live in a context of preserved autonomy with the experience of having some control over life for the last time, and patients should have the opportunity to prepare for the end of life while maintaining self-image and dignity.

The patient's participation is a prerequisite for good care, which also relates to ethical principles and evidence-based action [2]. In fact, the importance of participation is clarified in Swedish law, where the Swedish Patient Act mandates that participation in healthcare requires that care-related activities take place in consultation with the patient and there is room for the patient's wishes and conditions $[3,4]$.

It is necessary for patients to make decisions about their own deaths so that the end of life can be as good as possible [5]. Patients who are introduced to this concept early may be more likely to participate in how and where they are to be cared for and die. In addition, patients should know that starting this planning early will extend the time and opportunity to change their minds about these decisions and can also increase a patient's motivation and satisfaction, thereby reducing stress and anxiety $[6,7]$.
Many decisions should be made with the mutual cooperation of the patient, their relatives, and healthcare personnel. However, this interaction is like a wave bowl, where the weight moves in different directions depending on the situation [2]. There should also be respect for the fact that not all patients want to be familiar with their future care, as many see it as being taken 'away from life '[6]. Thus, caregivers have a significant responsibility to be sensitive to when a patient is ready for conversation and, if necessary, asking the patient difficult questions [5,8].

Palliative care aims to relieve suffering and promote quality of life for patients with progressive, incurable diseases or injuries [9]. Most of those receiving palliative care wish to be cared for at home [10]. However, the desire to die at home often wanes as the course of the disease lengthens, and the last stage in life is often characterized by alternating between feelings of security and insecurity $[10,11]$.

${ }^{\star}$ Correspondence to: Lise-Lotte Jonasson, Senior Lecturer, Faculty of Caring Science, Work Life and Social Welfare, University of Borås, SE - 50190 Borås, Sweden, Tel: 46703197078, E-mail: lise.lotte.jonasson@hb.se

Key words: adult patients, end-of-life, interview, life situation, palliative home care, participation

Received: April 10, 2018; Accepted: May 09, 2019; Published: May 13, 2019 
Palliative care is often provided and carried out in the patient's home, meaning that responsibility for medical measures should be coherent over time, and all actions and interventions should be preceded by care planning [12]. As a result, home care is increasingly complex, and the caregiver should have the competence to balance between proximity and distance in their relationships with the patient and the relatives of the patient in the home $[12,13]$.

\section{Aim}

This study describes adult patients' experiences of their life situation and their participation in palliative home care.

\section{Methods}

\section{Design}

An inductive design with a reflective lifeworld approach was used [2]. The study was performed in 2018 in Sweden, where six adult patients were interviewed. All patients were receiving palliative care at home and lived in a medium-sized town in an urban area. Data were collected via interviews and analysed using phenomenological meaning analysis $[2,14]$.

\section{Sample and procedure}

Information about the study was first given by phone to fourunit managers of five municipal home care teams in a medium-sized town in Sweden. One-unit manager declined to participate in the study due to high workload. Four-unit managers approved the study, and they received information letters and consent forms via email, with information for the patient-responsible nurses and the request for the patient also attached. The unit managers talked to the patientresponsible nurses, who in turn asked patients if they wanted to participate in the study. The patients also received written information about the study and a request to participate.

The inclusion criteria were patients who were 18 years old and older at the end-of-life and receiving palliative home care. In addition, break point conversations had to have been carried out with the responsible physician. A break point call is defined as a conversation between the patient and the responsible physician where it is explained to the patient that there is no longer any curative treatment and that care should switch to palliative care with a focus on relief.

The patient-responsible nurses provided the names of patients who wanted to participate in the study. A total of 10 patients were asked; one declined, and three died. The study thus consisted of six patients, three women and three men ages 62 to 72 years old. All gave their informed consent to participate in the study. One of the authors booked the patients for interviews.

\section{Data collection}

The patients all chose to be interviewed in their homes. Prior to each interview, the participant was promised confidentiality, informed that their participation was voluntary, and told that they could discontinue participation at any time. Then patients were asked to give written informed consent to participate in the study.

An open interview technique was carried out, meaning that the interviews started with an initial question about the patient's experience of existence with a life-threatening disease. Thereafter, the patients were free to describe their participation in their care, how the care functioned, and their choice of location for the end-of-life. The introductory question of an open interview must be phrased in such a way as to get the patient directed towards the relevant area and be simple enough that it creates a relaxed mood [2]. The interview should be designed with two different kinds of questions: targeted questions and follow-up questions. An example of a targeted question is "Can you tell how it felt to receive such a message?" with follow-up questions being along the lines of "How did you react to it?" and "How did you feel then?" Two test interviews were conducted to assess the questions and layout. The test interviews did not lead to any changes, so the original design was used for the study. The interviews lasted for 40 to 60 minutes and were digitally recorded to be transcribed verbatim within a short time frame after the interview.

\section{Data analysis}

A phenomenological meaning analysis was carried out, involving the following steps [2]. The interviews were transcribed verbatim soon after the interview and were first read in their entirety by two of the authors (PL, TL) separately several times in order to get an overview of the content related to the study's aim. Thereafter, the analysis continued with the same two authors (PL, TL) for identifying meaning-bearing units. The identified units were then sorted meaningfully into a new document in order to more easily pay attention to what was expressed in the material. This clustering based on meaning gave an overview of the material and resulted in different elements of meaning with varying degrees of abstraction. After repeated discussions among all the authors, the essence was clarified. Ultimately, the analysis led to one essential meaning and five meaning elements.

\section{Ethical considerations}

Conventional ethical principles in humanitarian and social science research, as formulated in ethical research guidelines and in Swedish testing ethics legislation, were followed with regard to account information, consent, confidentiality, and usage requirements [15].

\section{Results}

The results are presented through one essential meaning and five elements that describe the phenomenon of life situation and participation in palliative care at home, as it is experienced by patients. The essential meaning was in regard to the need and endeavours to live as usual and take responsibility for life. The five essential elements that impacted the essential meaning were identified as 1) the home should be my home, where I know who is coming through the door; 2) I should know when help is coming and be included when decisions are made; 3) routines should be maintained, but without booking up tomorrow; 4) accept death, feel hope, and plan for relatives after my death; and 5) be aware that death is imminent, but not know when it will come.

\section{Essential meaning}

Participation in the end-of-life was experienced as a need to take responsibility with life to the end and as a desire to maintain basic human dignity. Participation is a deep human desire that is linked to life itself. Patients' desires to continue being a responsible person were aimed at small and large decisions in everyday life. It was important to maintain relationships and continuity related to control, and in order to maintain a pursuit of autonomy, various ways of taking control and deciding should be developed.

Dependence on help from outsiders joined with the striving for responsibility. The ability to make decisions about their own lives was experienced as diminishing when the disease and suffering progressed. Somewhere on the path of suffering, an acceptance arose 
that responsibility must diminish as death comes closer. However, the hope to have responsibility around what happens in the home was held for longer. There was a striving to be responsible for the last decisions in life, which becomes a paradox when the end-of-life goes beyond the human potential for responsibility. Responsibility could then be directed towards the survivors and focus on the opportunity for patients to live on through their relatives.

\section{The home should be my home, where I know who is coming through the door}

The home was the optimal place to be participating in life while preparing for death. The patients expressed strong reluctance to be cared for in hospitals if it was experienced as a risk of losing personal habits and being treated as just one of the crowds. There was a fear that hospital care was based on routines. In the home, the patients lived at their own pace and decided how they wanted to live. The home was experienced as freedom, where the patient decided on chores and peacefulness could be had. Small daily activities like sitting and looking out the window were examples of living. By trying to live as before, it seemed that patients in palliative care felt alive. Spending their remaining time at home and keeping their habits was important. At the same time, the palliative care accompanying the last stages in life was characterized by a fear that the home would be transformed into a workplace for healthcare and that the caregivers would not respect the home's intimacy.

One came today who said, "Do you want your gruel today?" Yes, just such a thing, that someone knows what I want means the lot for me.

It was important to patients that they decide where the care would take place and to have their voice heard regarding all changes in the home. In order to limit the sense of intrusion in the home, it was considered positive for caregivers to be assigned certain specific spaces, which could be anything from a shelf in the kitchen to an entire room. The disease and death were often experienced as limited to a room in the home where treatments were performed.

What reminds me of my disease is in a special room here in the apartment. So, when the registered nurse comes and wants to start the drip or remove it, that's where we are. So, when I'm disconnected, I go out and close the door, so I don't have to see it. It feels good!

It was appreciated when the registered nurse, who was also usually the responsible nurse, took the time to listen and talk. A deeper, more caring relationship can arise in the home when the patient and caregiver have a personal relationship. However, there were some experiences of unwanted caregivers. It was difficult for patients to associate with new caregivers, which is deplorable since it is not merely professional knowledge that is requested. The patients emphasized how important it was to dare to talk with caregivers about their difficult life situation and to do so only with those whom they chose themselves.

It feels so nice to talk to someone who knows and understands how I have it and that there is someone who dares to talk about difficult things. Though it may not be all I want to talk about, I feel that I have someone that is easy to talk to.

Palliative home care was also characterized by dissatisfaction with home service, mainly because they were many different and unknown people who came and went, and those people were pressed for time. This led to patients not wanting to bother to ask their names. Letting unknown people into their homes was frightening and created uncertainty and being unable to influence the flow of caregivers was experienced as powerlessness.
You feel that insecurity when people run in and out, and you don't want it. You don't know who the person is at all.

The fact that caregivers walked in with dirty shoes was not unusual. Palliative home care can at times be characterized by a loss of control of one's home. This may lead to powerlessness that, in turn, leads to a decision not to end life at home. There was a feeling of having to keep track of the home service so that everything would be right. Patients experienced a need to have consideration for the caregivers but did not receive reciprocal consideration. There were situations that required repeated explanations of how something should be done. Altogether, it was experienced as tiring and impersonal.

Yes, the one who comes to my home and will help me must, together with me, come up with how it should go to help me.

It was significant to be a participant in designing the caregiving. A lack of trust that home services would provide services in a caring manner may be a contributing factor in patients not wishing to continue with palliative care at home. There was a desire to get help and care in a personal way and for the caregivers to be aware of how it should be done. Constantly having to repeat details of how the patient wanted the help to be provided was experienced as exhausting.

Yes, I had hoped for some more continuity and to build some kind of confidence in who knows my home and knows what I need, knowing what it is for me; that those who come will know how I want it.

The patients' situations meant living with conflicting emotions. Receiving home help from someone who is perceived as a stranger can still be experienced as a better alternative to spending the last days in a hospital or at another care facility. It seems that emotions are changeable and vary with the different practical situations that can occur when one is dependent on help from outsiders.

\section{I should know when help is coming and be included when decisions are made}

The availability of care was crucial for a patient's participation and security. Availability was characterized by the ability to call at any time and have a registered nurse answer questions or to have a home visit regardless of the time of day. The patients had an understanding that delays occur but felt more secure knowing that efforts would be made.

But then I can call when I want to get a diuretic injection. And I can call from morning to evening or night, and this ... now they come at six and seven in the evenings.

The patient's situations were characterized by a desire to feel control over everyday life in general. The patients wanted to know what time home services and registered nurses would arrive in order to minimize the intrusion on their private everyday lives. There was a desire to get information about what was happening and what options existed, particularly if it was no longer possible to have home-based palliative care at the end-of-life. There was a desire to participate in the last days and to come up with alternatives, and the importance of participating in decisions was repeatedly emphasized. The most important thing to patients was not necessarily to get their way; instead, the most important thing was to participate in making decisions.

Yes, I want to feel that I may be deciding on how I want it. It [does] not always [have to] be what I want exactly, but I want to participate and discuss it.

Patients stated that they were not always allowed to participate in making decisions. Sometimes, information required for making a 
choice was inadequate or missing. Other times, it was difficult for the patient to take in information, such as not remembering any of the care planning done at the hospital. This indicates that there is a need for information to be given repeatedly.

\section{Routines should be maintained, but without booking up tomorrow}

Retaining routines was characterized by being able to socialize and receive visitors. At the same time, it was important not to plan too much and to take the day as it came, without a feeling of being all booked up. Patients adapted social activities as the day took shape. There was a need to have someone close by, but without requiring activity. Trying to maintain routines was emphasized by the patients despite the fact that their strength waned, and physical condition deteriorated. Disappointment was expressed by some over the fact that they did not even have the energy to go to the mailbox anymore.

We try to keep our routines as we always do. The best time is in the morning when the home service and registered nurse are with me. Then, we put on coffee and just sit down and take a rest in the kitchen. Eating does not work so well, for the nausea is so difficult. But we sit there and talk to each other if possible.

Being in the home environment surrounded by personal things had a good impact on patients' routines and independence. At home, patients could decide when they would be visited by friends and acquaintances. The home environment can prompt pleasurable thoughts despite suffering, and it is the place where the nearness of family was most felt. Being at home also made it easier to remember what happened during life.

If I am at home, then I have all my habits here, books and so on. So ... I mean, here, I can fuss over things.

The importance of family became more keenly felt as the awareness that life was running out increased. Being together with family could be soothing and joyful, even if the patient was lying down and just listening to dinner being cooked in the kitchen. Being together, rather than doing things together, was most important to the patients.

We [patient, mother, and daughter] have breakfast in peace and quiet, then we go and lie down in my bed together and read the newspaper, hugging a little.

Pain affected the patients' routines, particularly with being socially active. When hurting, a walk and the possibility of new impressions can relieve the pain and promote well-being. The pace of life and physical strength may be diminishing, meaning that a formerly rich social life is now over, but patients emphasized that joie de vivre can still be experienced despite disease. Therefore, being able to get away from home to maintain old relationships and create new ones was appreciated.

Then, I do not particularly have pain at that moment, so you can say that I have quality of life.

\section{Accept death, feel hope, and plan for relatives after my death}

The patients were aware that life now had a time limit. There was a desire to try to live as normal a life as possible and to live it for as long as it lasted. Patients expressed gratitude for life, in addition to disappointment. Trying to process experiences and preparing for death were approaches to a kind of acceptance of the fatal life situation.
I understand that there is no possibility of being cured. So I accept everything that comes. I mean, if you can play along for a while, then it's great. If this is not the case, then it is only to accept. I'm not at all worried.

To participate, being as independent as possible and responsible for their lives were emphasized by patients despite their circumstances. It took motivation to live on and not give up. Patients found it nice to talk about their life situations and existential issues with, for example, someone from the Swedish church. Such a conversation was perceived as different from what a curator at the hospital can offer. A spiritual faith may provide peace of mind and make the fear of dying manageable.

I am so humble, that I can accept this. Then, I have a strong Catholic faith that makes me not the least worried. But I try to be who I have always been, singing and talking. I try to create a joy around me.

Hope was characterized by a desire to live a little bit and to postpone death, to experience something special or experience having the body in control. There was also sometimes a hope of getting better, but when the disease conquered them, the focus of hope became more on dying peacefully. There was also hope that it would be good for relatives after the patient's death.

So, I have hope. No, not hope that I will survive, I cannot claim, but that it should be as good as possible for my survivors, it is my grandchildren. But it has felt very tough to have to leave. They won't have to follow me around anymore. I have made small boxes for them with things so they can remember me. It has been a way to process the situation.

It was important to participate in a good end-of-life by arranging the practical details, such as planning the funeral and getting finances in order, as much as possible, thereby relieving relatives of the burden. There was a will to take care of family properly, and preferably before weakness took over.

I have, as I said, prepared everything, practical things like finances and everything like that. So, it feels good that I have my wishes written down how I want it.

The patients were grateful for relatives' support. They did not want to be a burden or put too many demands on relatives. The consideration of relatives was a crucial reason for receiving home service, even though it was experienced as a major intrusion of privacy.

Because what I understand is that for the children and my wife, maybe they are the ones who are most afflicted. They are outside of the disease themselves, but they are always there every day.

There was a worry about how relatives would cope with the grief when the patient was no longer present. This worry was characterized by patients taking responsibility for relatives, even after their death. It was important to prepare everything that would go towards facilitating relatives' grief work.

He [the son] calls me three to four times a day just to see how I feel, and I am very happy that he does, but I would like him to take a little more distance. No, I'm not afraid of death. I am not, but I think of my loved ones.

\section{Be aware that death is imminent, but not know when it will come}

Not knowing where and when death would come was among the darkest thoughts' patients experienced. Existential stress characterized these experiences as having been robbed of their pension. Having to wait for death was associated with anxiety and a great deal of 
uncertainty about the future. It seemed like the paradox of life to still be strong-willed and determined yet unable to decide on the last crucial moment in life.

It feels worst to know that you no longer will play along; it is cruel. It is like sitting in the death cell and not knowing when you get the injection.

It was difficult to understand their situation when a patient neither looked sick nor felt ill. There was a kind of self-imposed exclusion, where conversations with relatives about vital life messages were deliberately disregarded, and thoughts about the future were minimized. To live a little longer than the forecasted time allotted was another extreme that could be experienced as living on borrowed time, which in turn led to dual feelings. The experience could be met partly with gratitude for being able to stay a little longer, and it could partly be experienced as painful. There was also a fear of how death would be experienced and anxiety about the moment of death. Such fears could lead to the patient trying to forget and not think about death at all.

But it is such a merciless situation I am in, both for my relatives and me ... to go and wait for death, not knowing when it will come. And it feels so hard.

Waiting for death was depicted variously by patients as "pulling down a blind" or not being a fun person to be with. That experience could provide insight into the finality of life that led to the patient getting a new hold on their life. The existential question "Why exactly me?" was also present along with a desire to not be alone at the end. Further, despite wanting to be home at the end-of-life, anxiety was expressed about not being able to make that decision. There was uncertainty about what the decisive factors in the decision would be, and that decision would push the patient to consider which place provided the greatest security. But often, the patient had insufficient knowledge of the help that is available.

Then, I do not know how it is in a hospice. I do not know; I just heard about it. But I do not know how it actually is. But it sounds like the outpost of death.

\section{Discussion}

\section{The home should be my home, where I know who is coming through the door}

The home had a central role in patients' lives and was seen as an optimal place to live out their remaining time. In the home, they experienced greater opportunities for participation and maintaining of everyday routines as compared to being in a care facility. This result is in line with research describing how home creates feelings of security and that home care provides an increased sense of independence $[11,16]$. At the same time, a sanctuary is a personal place where the individual is at home in an existential sense. This sanctuary is different for everyone and does not always correspond to the physical home [17]. Even in a homelike setting, the atmosphere can be negative, leading to feelings of homelessness [9]. Thus, being at home does not automatically mean that the patient feels at home and experiences a feeling of sanctuary.

To be cared for at home by unknown caregivers was perplexing and frustrating. The feeling of having the home environment changed and of constantly being reminded about their disease was described by patients as an emotional rollercoaster. This was consistent with previous research describing how increased dependence on other people and needing help in intimate situations can be difficult to handle and lead to a feeling of powerlessness [18]. But trust can be enhanced if a patient feels that they are seen and are important to the caregiver.
This result shows patients' dissatisfaction with how home services works, such as through the failure to show consideration for the patients and their homes and with the lack of continuity and time to spend with the patient. Letting unknown caregivers into their home felt offensive and uncertain to patients. Yet it was also impossible to get to know all the caregivers and having to always watch that everything was done right made patients feel insecure. Previous research has also shown that more caregivers can lead to a reduced feeling of security, and patients appreciate having one caregiver whom they know well [11]. Patients were more open and felt more secure with caregivers who knew them more personally. This study's results make clear that dissatisfaction with home services can be the deciding factor in where a patient chooses to be cared for in the last moment of life, and more research on this subject is needed.

\section{I should know when help is coming and be included when decisions are made}

There was a desire to create normality in everyday life. It was important to keep routines and to continue doing everything as usual as much as possible. Participation in planning for home visits was important. While the time itself usually did not matter, patients wanted to know when caregivers would be arriving in order to feel in control and to reduce the feeling of an intrusion on their everyday lives.

The results show that the availability of professional palliative care was of great importance for feeling secure in the home, which is in line with previous research demonstrating that availability was sometimes crucial when a patient chose to be cared for at home [11]. Availability can also create a sense of security for relatives, which can, in turn, enhance a sense of security for the patient. Availability is accordingly included in ethical values affecting what the patient may experience from caregivers, such as receiving and showing respect, facilitating participation, and acting professionally [19].

Participation in nursing is based on a shared responsibility between the patient and caregivers [20]. The healthcare system has a responsibility to ensure that patients receive sufficient information to be able to consider different options and that the patient has the last word. Patients must be prepared through trust, understanding, and being confirmed as a central person in order to be able to participate in caregiving decisions. It is also important that the patient is not placed in a subordinate position.

The results of this study showed that patients wanted to participate in everything that happened around them. Participation in their care can be a positive element for being able to process grief, and routines must be redesigned in order for it to work. The results revealed the importance of flexibility and consensus among all caregivers with regard to patients' participation in their care. Previous research has shown that patients experienced security when seeing collaboration and cooperation among all the concerned caregivers [11,20].

The patients wanted ongoing information about future planning, which confirms earlier research showing that information is crucial and the basis for a patient's participation in making decisions [11]. They wanted to know what options were available if being at home until the end would not work. There was a distrust that home services would appropriately manage care towards the end. Shortcomings in home service were a decisive factor in not remaining at home until the endof-life, even though that is what patients really wanted. Therefore, patients sometimes chose to apply for a hospice site or an open return at a care ward. This result confirms previous research that emphasized 
the importance of retaining dignity late in life through good palliative care [21].

\section{Routines should be maintained, but without booking up tomorrow}

Patients who received palliative care in the home reprioritized their everyday world based on their state of health, and things that were previously insignificant could take on greater value. Everyday life was taken as it came, and it was important to maintain social contacts in order to continue to feel alive. Previous research highlighted how patients in end-of-life care try to create small meaningful events in their everyday lives and get a chance for rest and reflection. Patients who were aware that life was limited had a desire to take advantage of every moment and/or be able to stop time [22]. Living with an incurable disease means a destiny that cannot be avoided [2]. Everyday life is affected and help from professional caregivers could be needed in order to experience well-being despite the illness.

These results emphasize the importance of being with relatives. This is in line with earlier research showing that the most important resource for both the patient and their relatives is family [23]. The patients talked about how isolated and lonely they felt because difficult symptoms created an obstacle to social interaction. These results back up previous research showing that disease and intense suffering can contribute to closing a patient off from the outside world, causing involuntary isolation [16]. To be physically restricted and suffering from severe symptoms limits human contact. If a community of relatives is not available, a difficult-to-handle loneliness can arise through the experience of no longer existing by not being included in future plans. Existential loneliness can also be experienced when care is inadequate or absent [17]. According to previous research, thoughts of death can be kept away through affinity with and participation in everyday life [24].

These results show the patient's need for comfort to relieve grief. There were little things that made a difference. Everyday life must work well in order to have a sense of well-being, but when something serious happens, everyday life is rocked, and nothing is a matter of course any longer. But being met with kindness, joy, and love made life more bearable. Positive interactions can be crucial for providing the energy to continue living. Previous research has indicated that the way caregivers interact with older adults affects the patient's experience of health [25].

The patients did not recognize themselves in the situations they were in. It was sometimes difficult to explain their feelings to relatives for fear of hurting them, and this is consistent with previous research [24]. Suffering was a reminder of how life-threatening the disease is, and patients felt it could not be shared with other people. This may be why they often expressed existential loneliness [24]. This result highlights patients' loneliness and vulnerability despite social safety nets, and the patients in this study wished that their loneliness would be met with empathy and respect for their surroundings. It may be crucial to be seen and heard by caregivers in order to feel participation in life and have a sense of security. This is in line with previous research demonstrating that inner security is dependent on feeling a sense of affinity $[2,11,18]$. When life was exposed to threats, patients could feel insecure, but security could be regained by getting certainty and feeling understood $[2,18]$.

\section{Accept death, feel hope, and plan for relatives after my death}

The results highlighted patients' fear and anxiety about burdening relatives, and they wanted to show the greatest possible consideration for their relatives. They were also afraid that the disease would affect everyday life too much. This fear confirms previous research, where fears were expressed about being unloved because of physical and mental changes as death approached [16]. The results in this study showed that the patients were preparing for their death as their health deteriorated. Some planned in detail, while others told relatives how they wanted things to be handled towards the end. Depending on relationships with relatives, it can be difficult to prepare for death. The patients also experienced the difficulty of living and dying. Patients wanted to feel independent, if only for a while. Losing their autonomy and feeling like a burden felt similar to losing their dignity, and the feeling of being a burden to their relatives turned out to be a heavy load to carry. Corresponding results are described in the research literature, finding that it may be common for patients in palliative care to plan their own death to facilitate relatives. In addition, patients may write letters or diaries to their children or grandchildren to leave behind [26].

In the results of this study, hope was expressed not for survival but to live as long as possible. Through short-term goals in everyday life, such as taking a short walk or managing their daily hygiene, the patients managed to maintain hope. The patients re-evaluated what was important in life and how the focus was now on achieving a nice ending of life. It turned out to be important to spend their remaining time with family and friends. It was obvious how conscious the patients were that their time was limited. Here, the feelings shifted between gratitude and disappointment. Hope had never been gone from life, but when the end approached, hope changed character to become a hope to die peacefully. Previous research confirms the importance of hope in order to more easily keep the threat of dying at a distance $[18,22]$. For the patients, with hope, it became easier to feel well-being even though they were facing death. And when there may have been false hope, it could create an opportunity to survive psychologically.

The experience of hope in this study was marked in the midst of the gloom, even bringing happiness, laughter, and light. The jump to hope served as a "drug," even bringing good symptom control so that, on the path to death, the suffering could be alleviated. This result is also consistent with previous research, where loss of hope was described as tipping over the edge, where there was no meaning in life [22]. When the patient lost hope, it meant abandonment, and only death remained. None of the patients in this study were ready to die, and they were saddened by the fact that life was running out. They experienced strong feelings about this, including anger, despair, and powerlessness.

\section{Be aware that death is imminent, but not know when it will come}

The results in this area showed that the patients were in a prolonged dying process that is difficult to relate to. There was a fear of how the moment of death would occur. Therefore, they often chose to push thoughts of death aside, in line with prior research that has also shown that patients sometimes ignored their prognosis [22]. It could manifest as a feeling of having to stay strong for relatives and friends. The results in this study showed how patients initially denied their fate but then passed through to acceptance as their body became increasingly fragile. It emerged that thoughts of death could be kept away by occupying oneself. Once the acceptance came, however, the patients made the best of the situation and the time they had left. This is in line with research describing what it is like being in a distressed body, where activities must be cancelled at the last minute [16]. As the health condition worsened and complications arose, patients' quality of life deteriorated markedly. An existence of uncertainty, where the death sentence controlled their whole life, made patients say that they are prisoners in 
their own bodies. On the other hand, research has shown that a dying man can reduce his suffering by distancing himself from the sickness, thereby releasing joy and desire [17].

Patients suffering from incurable diseases and are at the end-oflife are in and out of an existential crisis. Death looms over them as a threat. Confrontation with their own mortality can be merciless and lead to emotional suffering. It is also not uncommon for patients to suffer from anxiety levels that can be difficult to handle. Being in the waiting room of death but not knowing the moment when death will come can become an anxiety-filled experience of uncertainty that is frightening and threatening. This is made apparent by previous research that emphasized the challenging experience of being at the end-of-life [18]. Human beings are vulnerable and have limited resources for combatting the difficult situation they are in, where confrontation with their own understanding of death raises an anxiety in which existential issues become central [18].

These results highlighted a desire to not end their lives in hospitals, which did not leave many alternatives. The difficulties that arose in the home were a contributing factor to the fear of dying there. But if the choice was between a short-term stay in the municipality's accommodations or a hospice, the choice was simple hospice. This study showed patients' uncertainty about being in hospice for their last days and whether they would get there at all. It should be a matter of course to die where it feels safest, and no one should be angry for decisions that are made. It can sometimes be seen that a move to hospice is perceived as giving up. It also turned out that the patients in this study would prefer not to decide in advance where their last time would be spent but wanted to choose from what it felt like in the here and now. Earlier research emphasized that hospice is a good alternative for end-of-life care if the patient is helped to share the burden of the last moments [27]. When the patient was staying at a hospice, relatives had the opportunity to gather their strength and have some time for themselves, which could be decisive for their energy. Relatives of patients at the end-of-life are often witnessing a patient's physical and emotional changes. These changes can have a strong impact on the psychological well-being of relatives and should be taken into account in a patient's care [23]. Patients at the end-oflife of life could feel relief about getting to hospice, and those who knew they had a hospice site when the end approached felt secure and perceived hospice as supportive for their relatives. Patients who wanted to die at home were completely calm and confident about it as well, but patients who could not die at home felt very bad about the uncertainty of how it would occur [27].

\section{Methodological considerations}

In order to achieve trustworthiness in the data and consistency presentation, the analysis was discussed within the research group. The intention was to describe the methods and results with quotes as clearly as possible. The Swedish context and the small sample size mean this study has limited transferability, but those in similar contexts can recognize themselves in the results. There were no ethical problems.

\section{Conclusions and clinical implications}

A patient's life situation and participation in palliative home care can be maintained and improved by caregivers acting as guests in the patient's home, building up the patient's trust, showing consideration for the patient and their relatives, promoting the belief that the patient can live their everyday life as they previously had, asking about the patient's habits, and showing that there is time to be given to the patient and continuity in the caregiving relationship. Educational efforts should increase for teaching caregivers how to have supportive conversations with a patient who is dying and preparing for death.

\section{Acknowledgements}

We are grateful to all of the study participants.

\section{Funding}

None.

\section{Conflicts of interest}

None.

\section{References}

1. National care program for palliative care (2012) Regional Cancer Center.

2. Dahlberg K (2014) To examine health \& care. Stockholm: Natur \& Kultur.

3. Health and medical care law (SFS 1982:763). Stockholm: Government and Government Offices.

4. The patient act (SFS 2014:821). Stockholm: Government and Government Offices.

5. Borreani C, Brunelli C, Miccinesi G, Morino P, Piazza M, et al. (2008) Eliciting individual preferences about death: development of the End-of-Life Preferences Interview. J Pain Symptom Manage 36: 335-350.

6. Barnes K, Jones L, Tookman A, King M (2007) Acceptability of an advance care planning interview schedule: a focus group study. Palliat Med 21: 23-28.

7. Sahlsten M, Larsson IE, Sjöström B, Lindencrona CS, Plos KA (2007) Patient participation in nursing care: towards a concept clarification from a nurse perspective. J Clin Nurs 16: 630637.

8. Werkander-Harstäde C, Andershed B (2004) Good palliative care: how and where? The patients' opinions. J Hosp Palliat Nurs 6: 27-235.

9. Saarnio L, Boström AM, Gustavsson P, Öhlén J (2016) Meanings of at-homeness at end-of-life among older people. Scand J Caring Sci 30: 312-319. [Crossref]

10. Neergaard MA, Jensen AB, Sondergaard J, Sokolowski I, Olesen F, et al. (2011) Preference for place-of-death among terminally ill cancer patient in Denmark. Scand J Caring Sci 25: 627-636.

11. Josefsson K, Bomberg M, Krans M (2018) Creating a sense of security in palliative home care: interviews with public health nurses. Nurs Palliat Care 3: 1-6.

12. Josefsson K (2010) Ten success factors for a good and safe home care for older people. Stockholm: Swedish Nursing Association and Careers Association.

13. Andersson H, Lindholm M, Pettersson M, Jonasson LL (2017) Nurses' competencies in home healthcare: an interview study. BMC Nurs 16: 65. [Crossref]

14. Polit D, Beck CT (2012) Nursing research: generating and assessing evidence for nursing practice, 9 th ed. Philadelphia: Wolters Kluwer Health.

15. Swedish Research Council (2017) Good research practice. Stockholm: Swedish Research Council.

16. Melin-Johansson C, Odling G, Axelsson B, Danielson E (2008) The meaning of quality of life: narrations by patients with incurable cancer in palliative home care. Palliat Support Care 6: 231-238. [Crossref]

17. Öhlén J (2000) Being in a sanctuary. Stories of relieved suffering in palliative care.

18. Sand L, Strang P, Milberg A (2008) Dying cancer patients' experiences of powerlessness and helplessness. Support Care Cancer 16: 853-862.

19. Jonasson LL, Liss PE, Westerlind B, Berterö C (2010) Ethical values in caring encounters on a geriatric ward from the next of kin's perspective: an interview study. Int J Nurs Pract 16: 20-26. [Crossref]

20. Larsson IE, Sahlsten MJ, Sjöström B, Lindencrona CS, Plos KA (2007) Patien participation in nursing care from a patient perspective: a Grounded Theory study. Scand J Caring Sci 21: 313-320. [Crossref]

21. MacArtney JI, Broom A, Kirby E, Good P, Wootton J, et al. (2015) On resilience and acceptance in the transition to palliative care at the end of life. Health (London) 19: 263-279. [Crossref] 
22. Olsson L, Östlund G, Strang P, Grassman EJ, Friedrichsen M (2011) The glimmering embers: experiences of hope among cancer patients in palliative home care. Palliat Support Care 9:43-54.

23. Drentea P, Williams BR, Bailey FA, et al. (2016) "He's on his dying bed": Next-of-kin's experiences of the dying body. Death Stud 40: 1-10. [Crossref]

24. Sand L, Strang P (2006) Existential loneliness in a palliative home care setting. $J$ Palliat Med 9: 1376-1387. [Crossref]
25. From I (2011) Health and quality of care from older peoples' and formal caregivers'.

26. Moestrup L, Hansen HP (2015) Existential concerns about death: A qualitative study of dying patients in a Danish hospice. Am J Hosp Palliat Care 32: 427-436.

27. Broom A, Cavenagh J (2010) Masculinity, moralities and being cared for: An exploration of experiences of living and dying in a hospice. Soc Sci Med 71: 869-876. [Crossref]

Copyright: (C2019 Jonasson L. This is an open-access article distributed under the terms of the Creative Commons Attribution License, which permits unrestricted use, distribution, and reproduction in any medium, provided the original author and source are credited. 